\title{
Silica Induced Lung Fibrosis Is Associated With Senescence, Fgr, and Recruitment of Bone Marrow Monocyte/Macrophages
}

\author{
AMITAVA MUKHERJEE ${ }^{1}$, MICHAEL W. EPPERLY ${ }^{1}$, RENEE FISHER $^{1}$, WEN HOU ${ }^{1}$, \\ DONNA SHIELDS ${ }^{1}$, HONG WANG ${ }^{2}$, JOEL S. GREENBERGER ${ }^{1}$ and LUIS A. ORTIZ ${ }^{3}$ \\ ${ }^{1}$ Department of Radiation Oncology, UPMC Hillman Cancer Center, Pittsburgh, PA, U.S.A.; \\ ${ }^{2}$ Department of Biostatistics, University of Pittsburgh, Pittsburgh, PA, U.S.A.; \\ ${ }^{3}$ Department of Environmental Health, University of Pittsburgh, Pittsburgh, PA, U.S.A.
}

\begin{abstract}
Background/Aim: The role of senescence and bone marrow-derived cells in silica-induced pulmonary fibrosis is unknown. Materials and Methods: C57BL/6HNsd, p16 ${ }^{+/ L U C}$, and tdTOMp16+ mice were intratracheally injected with 200 $\mathrm{mg} / \mathrm{kg}$ crystalline silica or irradiated $(20 \mathrm{~Gy})$ to the thoracic cavity and followed for the development of lung fibrosis. Results: The p16 ${ }^{+/ L U C}$ mice demonstrated senescence by day 7 after silica exposure. C57BL/6 mice exposed to silica demonstrated upregulation of p16, p21, and tyrosine kinase Fgr by day 7, whereas thoracic irradiation induced $p 21$ and Fgr by day 50 and p16 by day 110. Silica exposed GFP+ bone marrow chimeric C57BL/6 mice demonstrated senescent cells and $g f p+/ F g r+$ monocyte/macrophages in the lungs on day 21. The Fgr inhibitor TL02-59 abrogated monocyte/macrophages recruitment in in vitro transwell experiments. Conclusion: Both silica and radiation exposure induce senescence and upregulate tyrosine kinase Fgr for the recruitment of bone marrow-derived monocyte/macrophages and the development of pulmonary fibrosis.
\end{abstract}

Silicosis is associated with black lung disease (coal miner's disease) and remains a significant cause of environmental lung disease (1-14). Studies of lung specimens from patients suffering from silicosis and other causes of pneumoconiosis have demonstrated that there is a sequence of events including pulmonary epithelial cell damage, an inflammatory response involving both alveolar and interstitial pulmonary

This article is freely accessible online.

Correspondence to: Joel S. Greenberger, MD, FACRO, FACR, FASTRO, Professor and Chairman, Department of Radiation Oncology, UPMC Hillman Cancer Center, 150 Centre Avenue, Rm. 533, Pittsburgh, PA 15232, U.S.A. Tel: +1 4126473602, Fax: +1 4126476029, e-mail: greenbergerjs@upmc.edu

Key Words: Crystalline silica, silicosis, monocyte/macrophages, Fgr. macrophages, and increased numbers of alpha-smooth muscle actin positive cells in areas of fibrosis. This process, which replaces functioning lung tissue with fibrotic cells, often leads to fatal lung fibrosis $(1,9,15-27)$.

The role of senescent cells in the etiology of pulmonary fibrosis is a current subject of interest (28-35). Senescent cells have been shown to accumulate in the lungs during evolution of several causes of fibrosis, but their role is unknown (31, 34-36). Furthermore, the phenotypes of senescent cells, and their time course of appearance have not been documented in silicosis. In the present study, we elucidated the time course of appearance of senescent cells in the lungs of crystalline silica injected p16 ${ }^{+/ L U C}$ mice (37) in which images were captured on live mice based on the expression of the luciferase reporter gene, which is linked to p16 gene promoter. We also sought to elucidate both the phenotype and function of senescent cells in the lungs of tdTOMp16+ mice (38) in which p16+ senescent cells express a Tomato (red) reporter gene, which allows red cells to be sorted from explanted lungs. We have corroborated our results from the silicosis mouse model with the radiation-induced pulmonary fibrosis model. We also determined the magnitude of bone marrow origin monocyte/macrophages recruited in the lungs using gfp+ bone marrow chimeric tdTOMp16+ mice (36). The results demonstrate the accumulation in the lungs of both bone marrow-derived monocyte/macrophages and neutrophils during the evolution of silicosis.

\section{Materials and Methods}

Mice and animal care. C57BL/6J, p16 +/LUC (37), tdTOMp16+ (38), and C57BL/6 gfp+ (36) mice were maintained according to Institutional Animal Care and Use Committee (IACUC) protocols and housed at 4 per cage. Animals were fed standard laboratory chow and deionized water.

Animals were injected intratracheally with $200 \mathrm{mg} / \mathrm{kg}$ crystalline silica (Corning, Inc., Glendale, CA, USA) dissolved in $100 \mu \mathrm{l}$ of PBS. Mice were imaged for senescence using a Xenogen IVIS Imaging System 200 Series (PerkinElmer, MA, USA), as described previously $(39,40)$. 
For lung irradiation, animals received 20 Gy single-fraction thoracic irradiation and were then maintained according to the IACUC recommended laboratory conditions. Mice were sacrificed at serial time points after thoracic irradiation $(0,50,75,110$, and 125 days) (40). Lungs were removed and representative lung lobes were tested by RT-qPCR for levels of detectable mRNA for $p 16$, $F g r$, and $p 21$.

Evolution of silicosis and assays for senescence. The $\mathrm{p} 16^{+/ \mathrm{LUC}}$ mice were imaged weekly using Xenogen IVIS Imaging System 200 Series (PerkinElmer) (39) and p16 positive cells associated with activation of luciferase were visualized by scanning animals injected with luciferin substrate according to published methods (39). Individual animals were scanned weekly. The C57BL/6J, and tdTOMp16+ mice were examined by histologic evaluation of explanted lung samples at serial times after crystalline silica injection. Staining of lung cells for collagen 1, alpha-smooth muscle actin, and p16 markers were assayed according to previously published methods (40). Counter-staining of sections was carried out using an antibody for the senescence associated tyrosine kinase Fgr (41).

Preparation of $g f p+$ bone marrow chimeric mice. Recipient adult mice were irradiated to 8 Gy total body irradiation (TBI) and $24 \mathrm{~h}$ later injected through tail vein with $1 \times 10^{6}$ gender mismatched gfp+ bone marrow (36). Bone marrow chimerism was documented by examination of the peripheral blood of recipients at serial time points, and those mice deemed to be chimeric had over $50 \%$ gfp+ leukocytes in the peripheral blood.

In vivo gfp + bone marrow migration assay. One month prior to the injection of silica into the thoracic cavity, tdTOMp16+ mice were irradiated and transplanted with gfp+ mouse bone marrow. Silica injected mice were sacrificed on day 23 and single cells were isolated and processed for cell sorting. The relative percentage of red senescent cells sorted from control and silica treated gfp+ marrow chimeric mouse lungs was measured. Expression of Fgr was analyzed by qPCR in tdTOM+ senescent epithelial cells that were also CD45-, CD326+, and in tdTOM+ senescent alveolar macrophages that were also $\mathrm{CD} 45+, \mathrm{F} 4 / 80+, \mathrm{CD} 11-$. The relative percentage of bone marrow derived gfp + monocyte/macrophage cells was quantitated by sorting from control and silica treated tdTOMp16+ chimeric mouse lungs.

In vitro transwell experiments. Senescent bone marrow derived irradiated (5 Gy, subconfluent cultures held for 10 days) tdTOMp16+ cells were sorted for $\mathrm{TOM}+$ (red) color and placed in Transwell cultures. Two types of transwell experiments were carried out. For induction of fibrosis biomarkers in target cells, senescent cells were placed into the top chamber separated from target mesenchymal stem cells (MSCs) derived from the adherent layer of long term C57Bl/6 mouse bone marrow cultures in the bottom chamber by a 0.4 -micron pore size membrane. For cell migration experiments, senescent cells were placed on the bottom of the chamber, and gfp+ bone marrow cells were placed in the top compartment of Transwell cultures separated by 3.0-micron pore membranes (42). The transwells were maintained in complete Dulbecco's Modified Eagles Medium supplemented with $10 \%$ fetal calf serum. The migration of gfp+ cells through the filter to the bottom compartment was measured by imaging the bottom wells and counting gfp+ cells relative to numbers of senescent TOM+ (red) cells. The phenotype of migrating gfp+ cells was determined by immunohistochemical staining using antibodies to markers of monocytes/macrophages and other bone marrow derived cell phenotypes according to published methods (42). The Fgr tyrosine kinase inhibitor TL02-59 has been reported $(41,43)$.

Cell migration assay. Irradiated bone marrow mesenchymal stem cells (stromal cells) $(5.0 \mathrm{~Gy}$ ) were sorted for tdTOM+ and tdTOM- cells and compared with non-irradiated cells. Each cell population was cultured in the bottom of transwells in the transwell culture system. The cell layer in the bottom chamber was separated from the top cell populations well by a 3-micron pore size membrane. Equal numbers of $\left(10^{5}\right)$ gfp+ marrow cells were added to the top chamber of each transwell. The Fgr inhibitor TL02-59 (10 nM) or RS504393 (Medchem Express, Mammoth Junction, NJ, USA) $(10 \mu \mathrm{M})$, or the chemokine (C-C motif) ligand 2 (CCL2) inhibitor, which is a CCR2 chemokine receptor antagonist, was added to the media. At $24 \mathrm{~h}$ later, the migration of gfp+ bone marrow cells into the bottom of the wells were imaged and cells counted. At $48 \mathrm{~h}$ later, the cells from the bottom well were further analyzed by MoFlo XDP (Beckman Coulter) Fluorescent Activated Cell Sorter (FACS) for the phenotype of gfp+ cells that had migrated from the top chamber of each well.

Immunohistochemical staining of lungs for fibrosis, senescent cells, and Fgr positive cells. Lung specimens were explanted at serial times after crystalline silica injection and immunohistochemically stained for collagen by Masson's Trichrome staining, for senescence- associated Beta-Galactosidase, p16, p21, p19 (40), and tyrosine kinase Fgr (41). Sections were counter-stained with a second monoclonal antibody for immunohistochemistry according to published methods (40).

Phenotype of sorted cells from the lungs of silica treated mice. We isolated cells from the lungs of silica treated mice including Ly6 $\mathrm{C}^{\mathrm{hi}}$ monocytes, which may exert a proinflammatory role in tissue injury. Their impact after injuries is poorly defined. The $\mathrm{C}-\mathrm{C}$ chemokine receptor 2, which is expressed on Ly6 $\mathrm{Chi}^{\mathrm{hi}}$ monocytes was used for phenotyping, since it is essential for extravasation and transmigration into injured tissues. A selective $\mathrm{C}-\mathrm{C}$ chemokine receptor 2 antibody $(20,44)$ was used to count Ly6Chi monocytes recruited into the lungs after silica exposure.

Immunostaining for monocyte/macrophages and neutrophils. At 28 days after the crystalline silica $(200 \mathrm{mg} / \mathrm{kg})$ injection into the thoracic cavity of mouse, lung cells were isolated from tdTOMp16+ gfp + chimeric mice. Lung single cell populations were immunostained and sorted for tdTOM+ and gfp+ cells. Gfp+ cells were then further sorted for alveolar macrophages (CD45+, F4/80+, and CD11b-), interstitial macrophages (CD45+, F4/80+, and $\mathrm{CD} 11 \mathrm{~b}+$ ), and tdTOM+ cells were further sorted for alveolar macrophages (CD45+, F4/80+, and CD11b-), interstitial macrophages (CD45+, F4/80+, CD11b+), epithelial cells (CD45-, CD326), and endothelial cells (CD45- and CD31). Cells from the lungs of non-irradiated $\mathrm{C} 57 \mathrm{BL} / 6$ mice were sorted for alveolar macrophages (CD45+, F4/80+, and CD11b-), interstitial macrophages (CD45+, F4/80+, and CD11b+), epithelial cells (CD45-, CD326+), and endothelial cells (CD45- and CD31). The relative percentage of each cell type was quantified from each sample. CD11b+ and CD11b- cells were stained and quantitated according to published methods $(44,45)$ CD31, CD11b and CD45 were purchased from B.D. Biosciences, (San Jose, CA, USA) and F4/80 and CD326 were purchased from Invitrogen, Thermo Fisher Scientific (Waltham, MA, USA). 
A

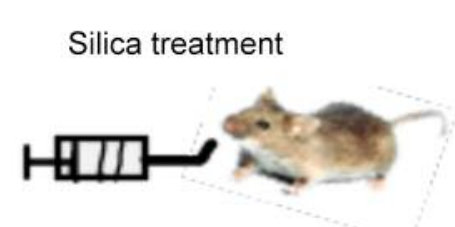

Days:

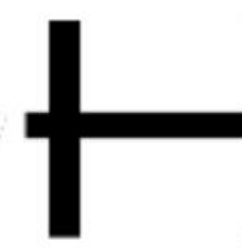

0
Day 6
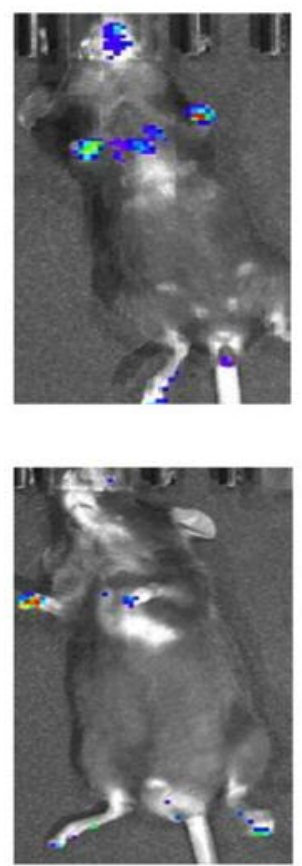

Day 13
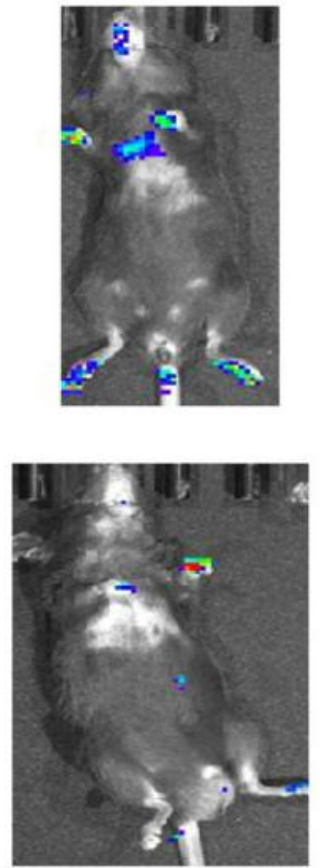

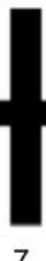

7

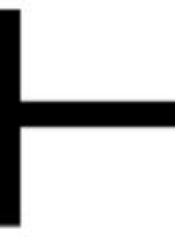

14

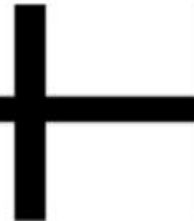

14
Day 20
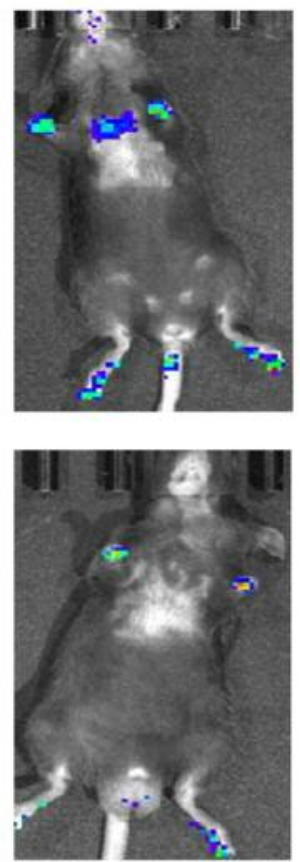

Day 27
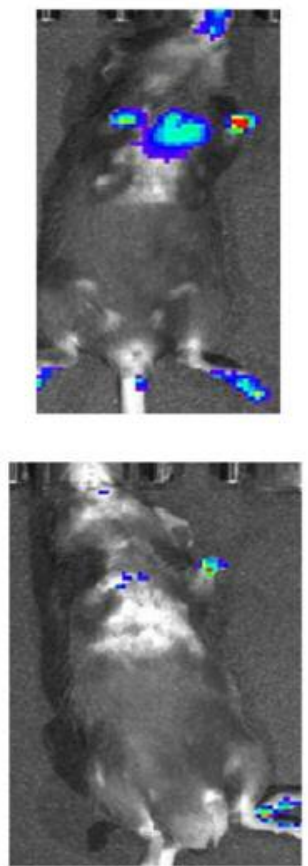

Figure 1. Crystalline silica induces senescence in the lung. Real time imaging of p16 ${ }^{+/ L U C}$ mice after intratracheal injection of crystalline silica (200 $\mathrm{mg} / \mathrm{kg}$ ). On days 6, 13,20, and 27 after injection, the mice were injected intraperitoneally with D-Luciferin (150 $\mathrm{mg} / \mathrm{kg})$, the substrate for luciferase. Ten minutes later, the mice were imaged using IVIS Lumina XR.

RNA isolation and cDNA synthesis. Total RNA was isolated from cell lines and explanted cells (tdTOMp16+ bone marrow stromal cell line, C57BL/6 bone marrow stromal cell line, and mouse primary tail fibroblasts) according to the protocol supplied with TRIZOLI Reagent (Invitrogen, ThermoFisher Scientific). The concentration of the RNA samples was determined using a microplate spectrophotometer Epoch, BioTech (Winooski, VT, USA) and cDNAs were synthesized from RNA $(2 \mu \mathrm{g})$ using high-capacity RNA-to-cDNA ${ }^{\mathrm{TM}}$ Kit (Thermo Fisher Scientific) following manufacturer's instructions.

Real-time PCR. Quantitative reverse transcription-PCR (qRT-PCR) was performed using a Biorad CFX-connect Real Time System instrument (Hercules, CA, USA), commercially available target probes and, Master mix (all from Applied Biosystems, Thermo Fisher Scientific). Detection of mouse Fgr, p16, Collagen 1 (CDKN2A), Transforming growth factor beta (TGF- $\beta$ ), $\alpha$-smooth muscle actin (Acta 2), connective tissue growth factor (CTGF), and Glyceraldehyde 3-phosphate dehydrogenase (GAPDH) was achieved using specific Taqman Gene Expression Assay reagents (Mm00438951_ml, Mm00494449_ml, Mm01192933_gl, Mm01257348_ml, Mm0060 0638_ml, Mm00725412_sl, Mm00802305_gl, Mm99999915_gl, respectively). Real time reactions were run using the following cycling parameters: $95^{\circ} \mathrm{C}$ for $12 \mathrm{~min}$, followed by 40 cycles at $95^{\circ} \mathrm{C}$ for $15 \mathrm{~s}$, and $60^{\circ} \mathrm{C}$ for $1 \mathrm{~min}$. Differential gene expression levels were calculated by the $\Delta \Delta \mathrm{CT}$ calculation.

Statistical evaluation. In the Fgr expression analysis, the qPCR analysis for the expression of TGF- $\beta$ and Collagen 3 , and the FACS analysis for gfp+ and CD11b+ cells, we compared cell groups with one-way ANOVA followed by the two-sided two-sample $t$-tests. For the other two group comparisons, we used two-sample $t$-tests or Wilcoxon rank sum tests where appropriate. $p$-Values less than 0.05 were regarded as significant. In these exploratory analyses, we did not adjust $p$-Values for multiple comparisons. 


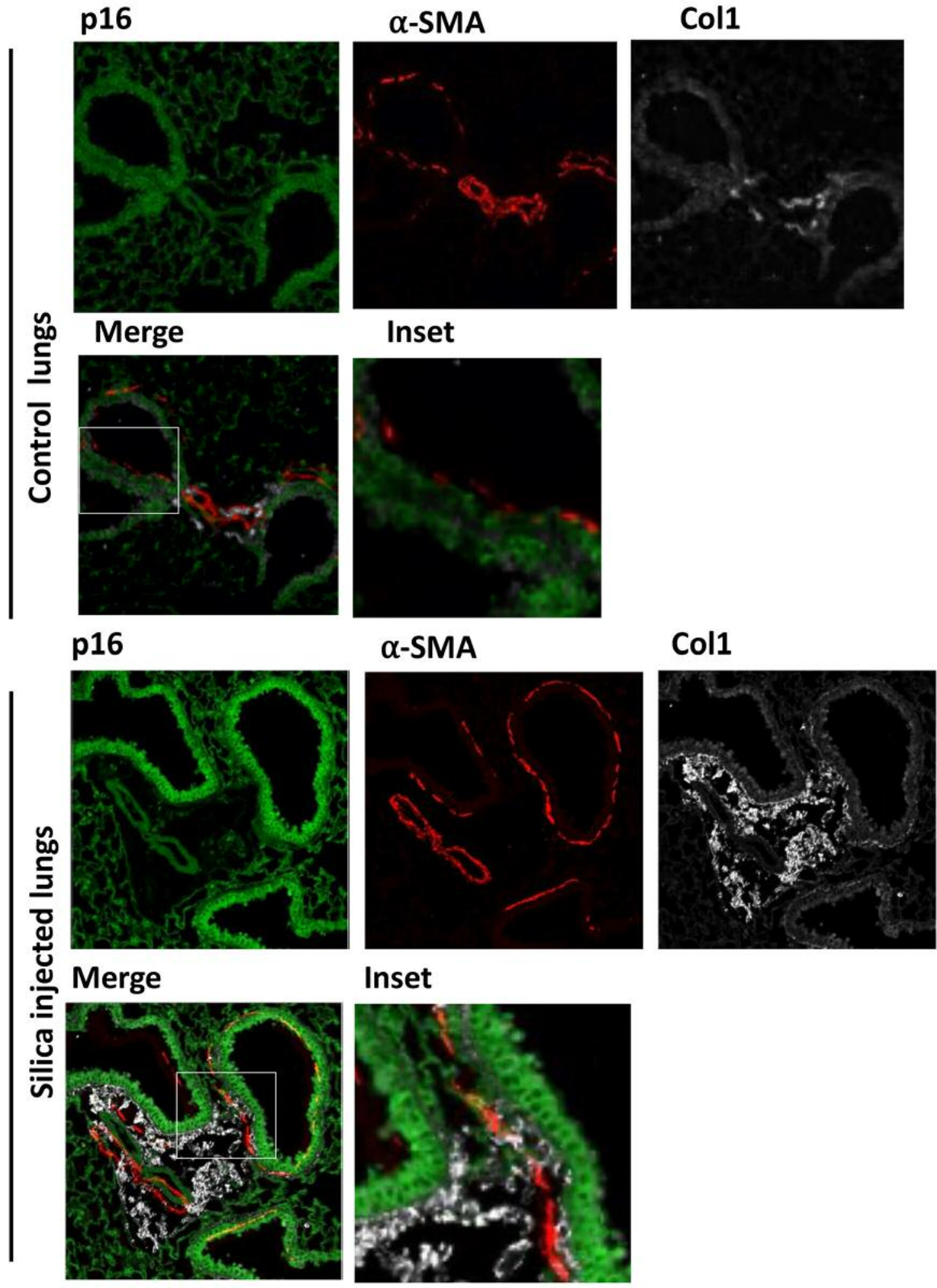

Figure 2. Silica induced epithelial senescence is associated with lung fibrosis. Control and silica-induced fibrotic mouse lungs were immuno-stained for p16 (green), alpha-smooth-muscle actin ( $\alpha$-SMA) (red) and Collagen1 (Coll, white). The upper two rows of photomicrographs show the airway of control mice and the lower two rows the airway of mice that received intratracheal silica $(200 \mathrm{mg} / \mathrm{kg})$. The inset in the silica-treated mice shows coll deposition in the vicinity of $\alpha$-SMA expressing cells that are behind the p16 positive green lung epithelium. Images are representative of 3 separate experiments. 


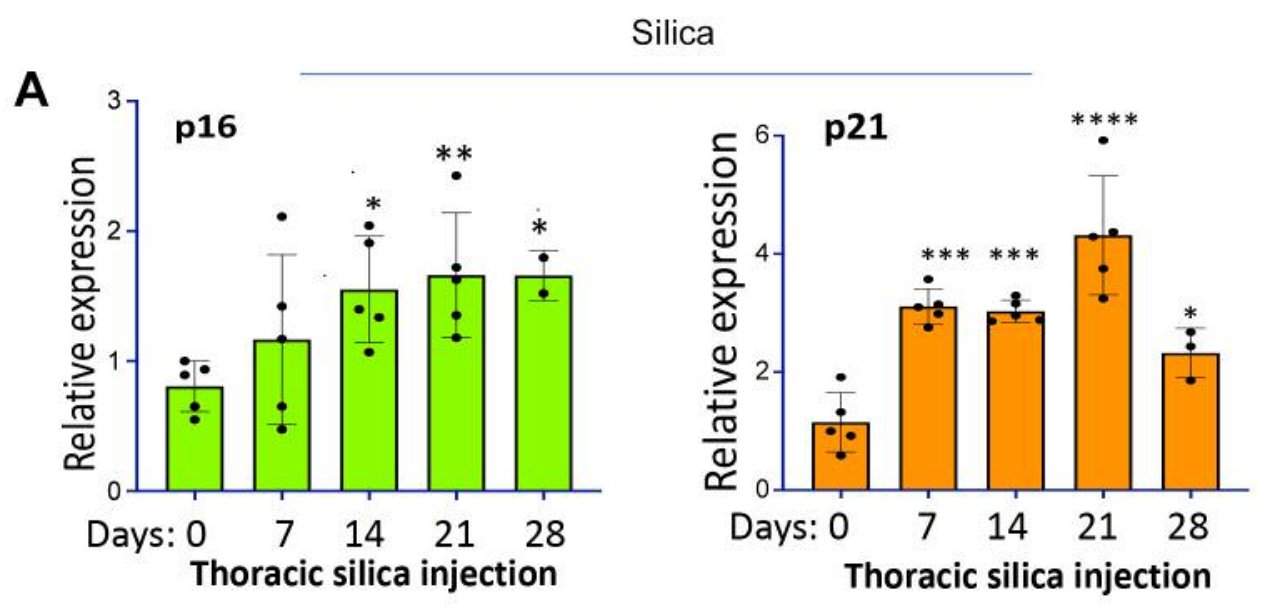

B

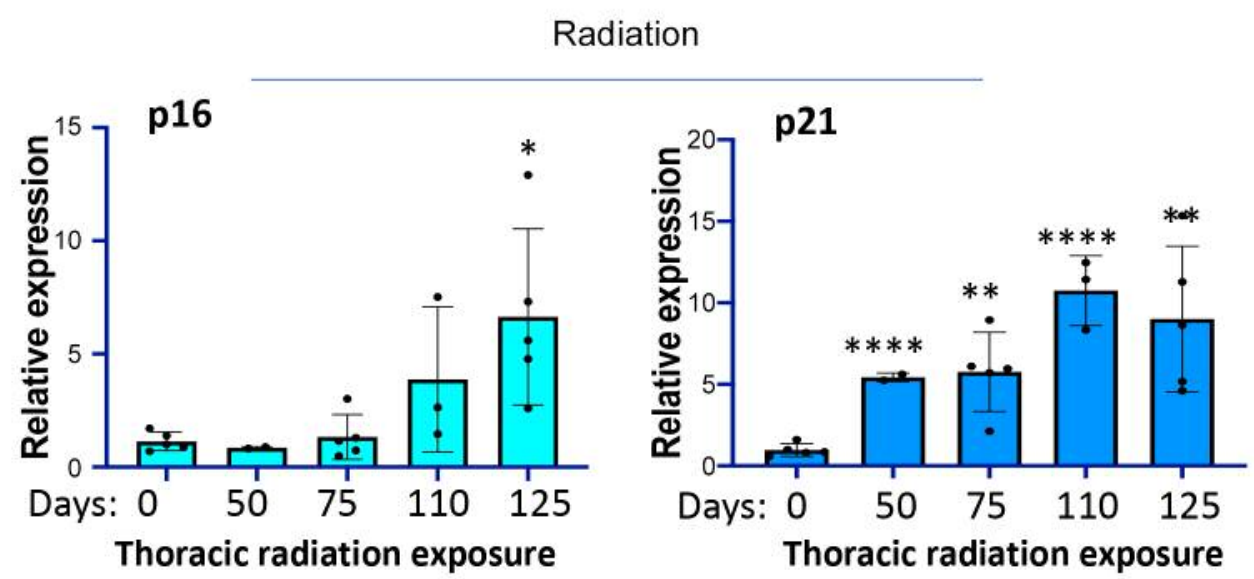

Figure 3. Induction of senescence precedes fibrosis in both silica- and radiation-induced pulmonary fibrosis. A) RT-qPCR on silica injected lungs at different days (days 0, 7,14,21 and 28) showing a time-dependent increase of senescent markers p16 and p21.B) RT-qPCR on thoracic irradiated $(20 \mathrm{~Gy})$ mouse lungs performed at different days (days 0,50,75, 110 and 125) showing time-dependent increase of senescent markers p16 and $p 21$ $(n=2-5, t$-test, $* p \leq 0.05 ; * * p \leq 0.01 ; * * * p \leq 0.001)$.

\section{Results}

Crystalline silica induces senescence in mouse lungs. We correlated the appearance of senescent cells in the lungs of crystalline silica injected mice with the time of first appearance of fibrosis in the lungs of mice by first determining the time of appearance of p16+ cells in serial imaging of $\mathrm{p} 16^{+/ \mathrm{LUC}}$ mice. As shown in Figure $1, \mathrm{p} 16^{+/ \mathrm{LUC}}$ mice injected with crystalline silica first showed detectable p16+ areas, following luciferin injection, as early as day 6 and the p16+ area increased over time. In contrast, mice not exposed to crystalline silica showed no detectable luciferininduced p16+ luciferase areas in the lungs.

Silica-induced epithelial senescence is associated with lung fibrosis. We next correlated the appearance of senescent cells in $\mathrm{p} 16^{+/ \mathrm{LUC}}$ mice, which was first detected by IVIS imaging, with the appearance of p16+ senescent cells in C57BL/6J mice using histochemical staining of explanted lungs. Lungs were removed from C57BL/6J mice on day 28 after silica injection and immunostaining was performed for p16, alpha-smoothmuscle actin ( $\alpha$-SMA) and Collagen 1 (Col1). The epithelial lining of the silica injected mouse lungs showed increased p16 staining (Figure 2, bottom panel) compared to the control lungs (Figure 2, top panel) and revealed the presence of senescent cells. The p16 expressing cells of the lungs were juxtaposed to the cells expressing $\alpha$-SMA, a marker for myofibroblasts. Col1 positive areas indicated the areas of fibrosis (Figure 2).

Senescence is detectable prior to pulmonary fibrosis in both cases of either silica-induced or radiation-induced pulmonary fibrosis. Lungs were removed at serial time points from either 
A
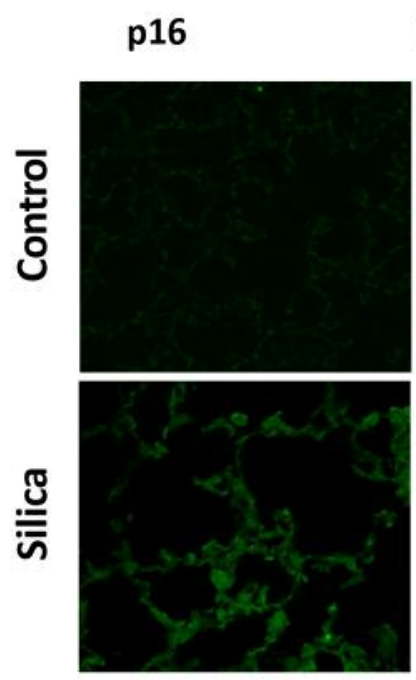

Fgr
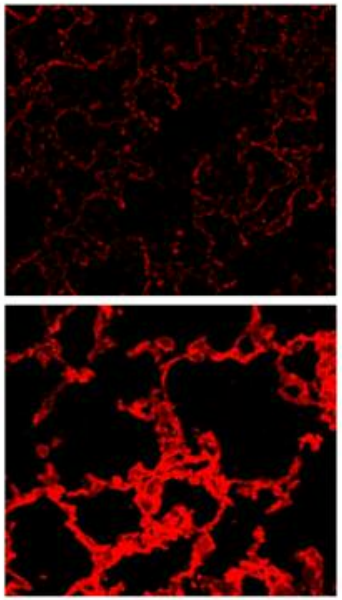

Merged

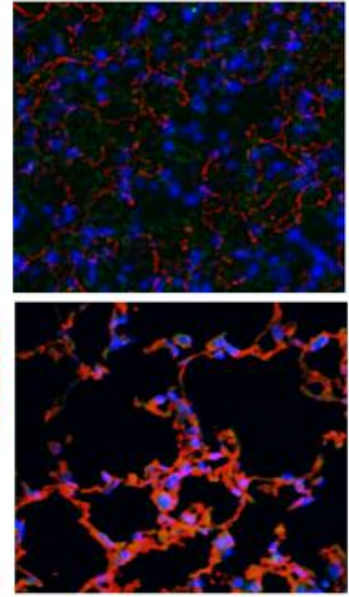

Radiation exposure

C p16

Fgr
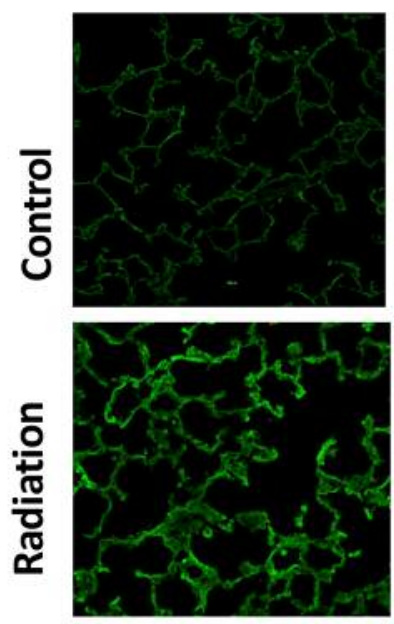
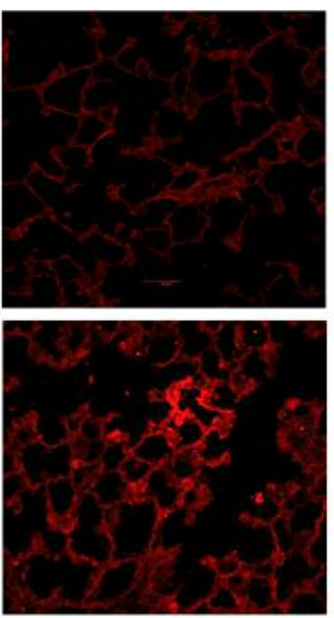

Merged
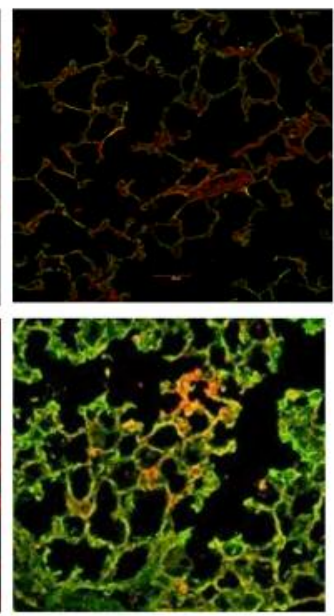

B

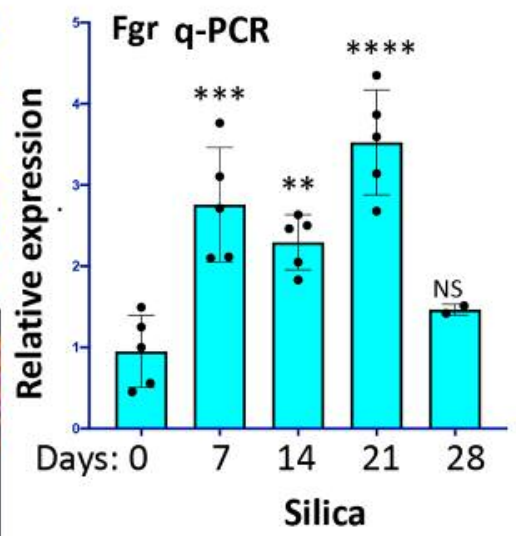

Figure 4. Induction of tyrosine kinase Fgr in both silica- and radiation-induced pulmonary fibrosis. A) Silica injected mouse lungs were immunostained for p16 and tyrosine kinase Fgr. B) RT-qPCR on silica injected lungs (200 $\mathrm{mg} / \mathrm{kg}$ ) at different days (days $0,7,14,21$ and 28$)$ showing a time-dependent increase of senescent marker Fgr. C) Thoracic irradiated (20 Gy) mouse lungs were immunostained for p16 and tyrosine kinase Fgr. D) RT-qPCR on thoracic irradiated (20 Gy) mouse lungs was performed at different days (days 0, 50, 75, 110, and 125) and showed a timedependent increase of the senescent markers $p 16$ and $p 21\left(n=2-5, t\right.$-test, $\left.{ }^{*} p \leq 0.05 ; * * p \leq 0.01 ; * * * p \leq 0.001\right)$.

silica-injected mice on days, 0, 7, 14, 21 and 28 (Figure 3A), or from thoracic irradiated mice on days $0,50,75,110$ and 125 (Figure 3B) and were analyzed for the expression of senescent biomarkers (p16 and p21) by qRT-PCR. In agreement with our earlier results (Figure 1), senescent markers (p16 and p21) were upregulated in a time-dependent manner in both models of pulmonary fibrosis. Interestingly p16 expression was delayed in radiation-induced pulmonary fibrosis although it was expressed before fibrosis (Figure 3B). These data confirm prior studies with thoracic irradiation showing that detection of significant numbers of senescent cells precedes the appearance of histologic fibrosis (40), and clearly demonstrate the appearance of fibrotic areas after prior detection of senescence. 
A

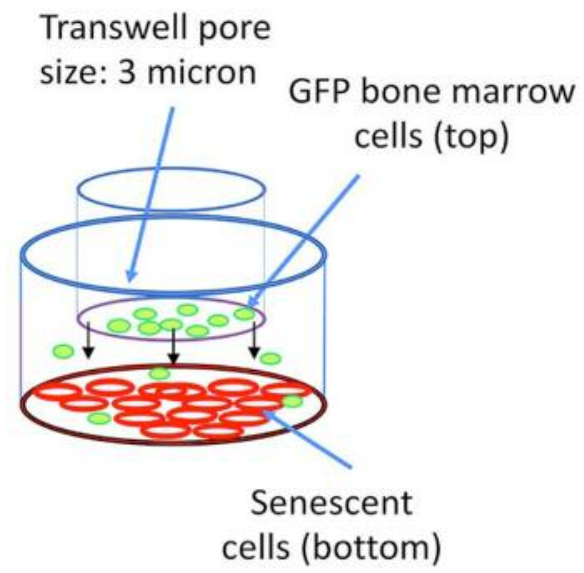

B

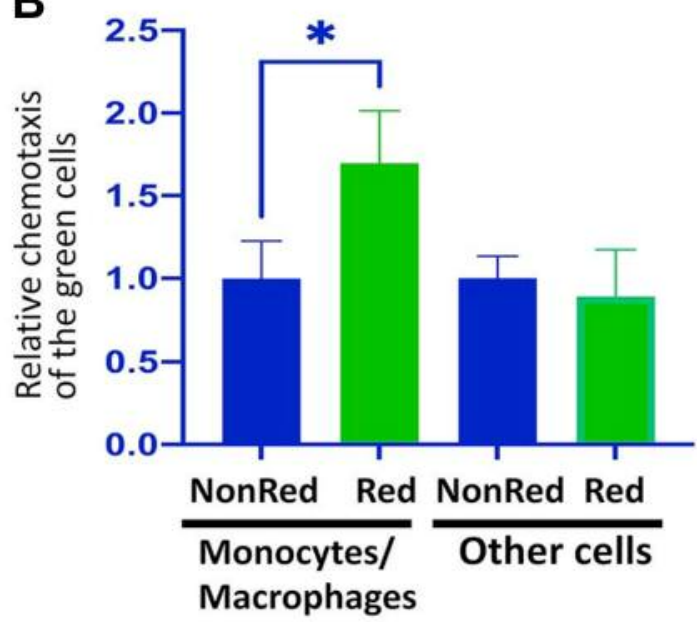

Figure 5. Senescent cell induction of migration of freshly explanted gfp + mouse bone marrow and, specifically, gfp+ monocytes/macrophages in transwell cultures. A) gfp+ marrow. Cells on the top chamber of the transwell system were separated by a 3-micron filter from sorted tdTOMp16+ senescent cells on the bottom chamber. B) At 48 h, bone marrow cells migrating to the bottom chamber were counted and immunophenotyped for cell surface markers of monocytes/macrophages or other marrow cells. Cells in the bottom chamber of the transwell system were either red sorted senescent cells (green bar), or irradiated but non-senescent (non-red) cells from the same irradiated culture (blue). Results are presented as mean \pm SEM of three separate experiments $(n=3 ; p \leq 0.05 ; p \leq 0.001)$. $p$-Values were calculated by $t$-test.

Tyrosine kinase Fgr is induced prior to fibrosis in both cases of either silica- or radiation-induced pulmonary fibrosis. In human idiopathic pulmonary fibrosis, the tyrosine kinase Fgr is upregulated and since tyrosine kinases are known to contribute to pulmonary fibrosis (46-52). Therefore, next we evaluated the expression of Fgr in either silica- or radiationinduced pulmonary fibrosis. Expression of $\mathrm{Fgr}$ was upregulated in both models of pulmonary fibrosis along with p16 (silica: Figure 4A and radiation: Figure 4C). To examine the expression of Fgr in a timedependent fashion, we analyzed either the silica-injected lungs on days, $0,7,14,21$ and 28 or the radiation-exposed lungs on days $0,50,75,110$ and 125 by qRT-PCR. Compared to control, Fgr was significantly upregulated either on days 7, 14, and 21 for silica- or on days 50,75 , and 110 for radiation-induced pulmonary fibrosis (silica: Figure 4B and radiation: Figure 4D). Interestingly Fgr expression decreased at the last time point for both models.

Bone marrow derived GFP+ monocytes/macrophages migrate towards radiation-induced senescent cells in a transwell coculture system. We next quantitated migration of freshly removed gfp+ bone marrow cells through the transwell filters in response to senescent cells placed in the bottom chamber of the transwells. Gfp+ bone marrow cells were placed in the upper compartment of transwells separated by 3.0-micron filter from red senescent cells in the bottom chamber (Figure 5). The schematic for the chemotaxis in the transwell system is shown in Figure 5A.
Bone marrow derived gfp+ cells migrated through the 3.0micron filters and were observed to accumulate in increasing numbers in the bottom chamber in close proximity to senescent cells. The migrating bone marrow cells were predominantly of the monocyte/macrophage phenotype but other phenotypes were also observed (Figure 5B).

In vivo, bone marrow derived monocytes/macrophages migrate towards silicosis lungs. To examine whether in silicosis lungs there was monocyte/macrophage migration, we performed FACS analysis of single cell suspensions of lungs from control or silica-treated mice on day 3 or day 21 . We analyzed F4/80 positive cells (Figure 6A) for the expression of Ly6C and CCR2 and gated for 4 different populations: 1) Ly6C- \& CCR2+ cells, 2) Ly6C ${ }^{\text {hi }} \&$ CCR2+ cells, 3) Ly6C\& CCR2+cells, 4) Ly6Chi \& CCR2-cells (Figure 6B). Ly6C is a marker to identify monocyte and macrophage subpopulations and $\mathrm{F} 4 / 80+, \mathrm{CCR} 2+$, Ly6C $\mathrm{C}^{\text {hi }}$ designate inflammatory monocytes. We found a significant increase in F4/80+, CCR2+, Ly6C ${ }^{\text {hi }}$ cells (53\%) in the lungs after only 3 days of thoracic silica injection compared to the control lungs $(19.2 \%)$. Interestingly, on day 21 there was a steep reduction of $\mathrm{F} 4 / 80+, \mathrm{CCR} 2+, \mathrm{Ly}^{\mathrm{C}} \mathrm{C}^{\text {hi }}$ cells $(9.4 \%)$ and a robust increase in $\mathrm{F} 4 / 80+$, CCR2+, Ly6C- cells $(71.8 \%$ ) (Figure 6B). When the F4/80+, CCR2+, Ly6C ${ }^{\text {hi }}$ cells were further analyzed for the presence of the CX3CR1 marker (Figure 6C), as it is present in the inflammatory monocytes in circulation, majority of monocytes $(94.6 \%)$ were CX3CR1 negative. 
A

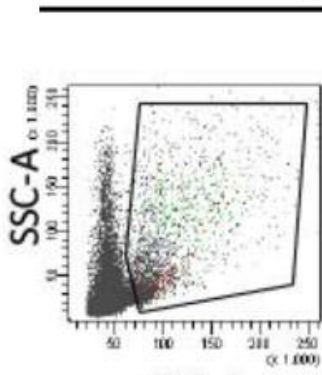

FSC-A

\section{Ctrl C57BL/6}

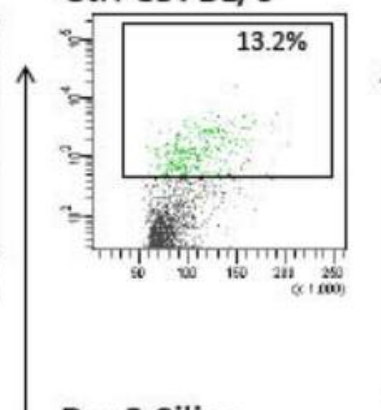

Day3 Silica

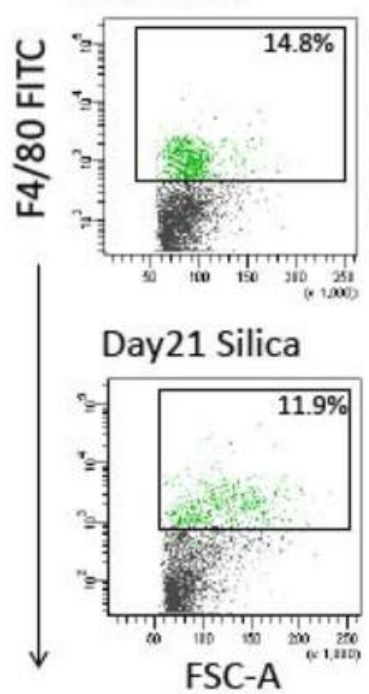

B
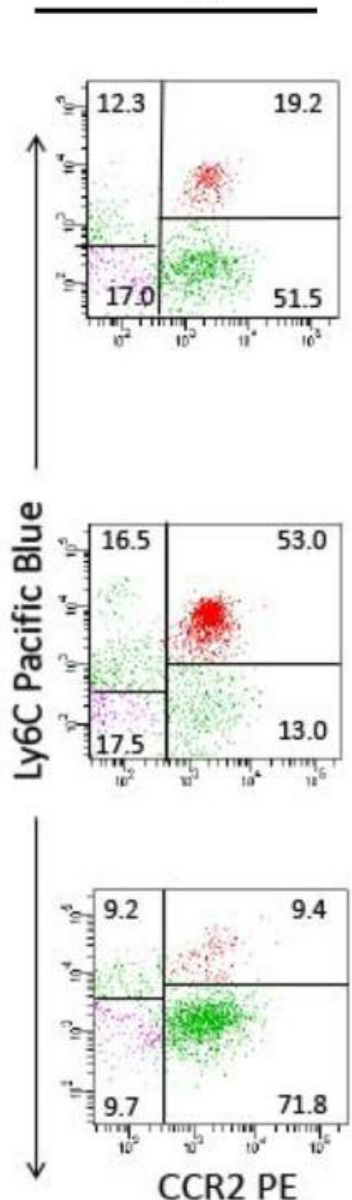

C

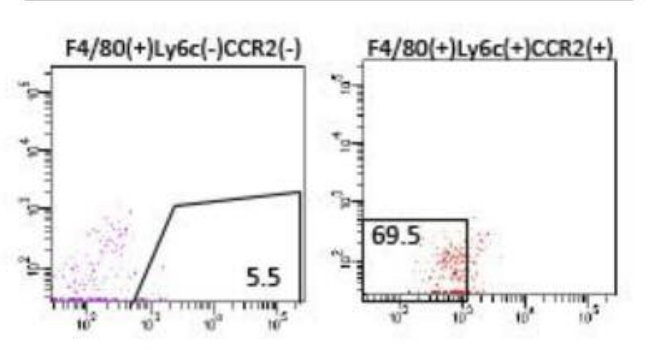

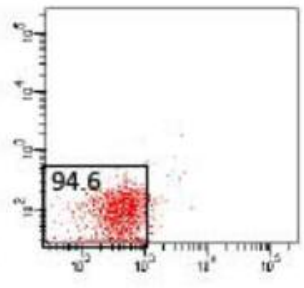
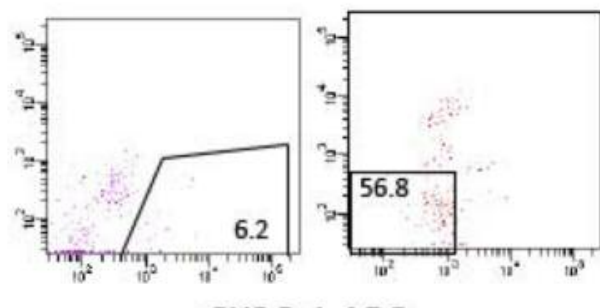

CX3Cr1 APC

Figure 6. Effect of silica on recruitment of monocytes into the lungs. Single suspensions of lung cells from control or silica-treated mice on day 3 or day 21 were (A) first sorted for F4/80 positive (green) cells. (B) The F4/80+ cells were analyzed for Ly6C and CCR2 and gated for 4 quadrants: (1) Ly6C-\& CCR2+cells, (2) Ly6Chi \& CCR2+cells, (3) Ly6C-\& CCR2+cells, (4) Ly6Chi \& CCR2-cells. (C) F4/80+, Ly6Chi \& CCR2+cells and F4/80+, Ly6C-\& CCR2- cells were further analyzed for CX3CR1 cells.

In silicosis lungs, tyrosine kinase Fgr expression is induced in senescent cells and in recruited bone marrow monocyte/macrophages. We next determined the phenotype of migrating marrow cells to the silica-injected lungs in vivo and quantitated the relative percentage of gfp+ monocyte/macrophages in previously bone marrow transplanted mice that were chimeric for gfp+ bone marrow. Recipient tdTOMp16+ mice that were transplanted with gfp+ bone marrow and were chimeric by analysis of peripheral blood on day 50 after bone marrow transplantation were administered with crystalline silica. As shown in Figure 7, there were significant numbers of bone marrow derived gfp+ monocyte/macrophages in the lungs of tdTOMp16+ mice that had been injected with crystalline silica 23 days previously. We found CD45+, F4/80+, CD11b- and CD45+,
F4/80+, CD11b+ cells in both transplanted GFP+ bone marrow cells that had migrated to the recipient lungs as well as in GFP-cells that are native to the recipient lungs. CD11b-population is designated as alveolar macrophages and CD11b+ cells are designated as interstitial macrophages (Figure 7). To evaluate the expression of Fgr in the lung cells 23 days after silica injection, we performed qRT-PCR after cell sorting. Baseline Fgr expression was significantly higher in alveolar macrophages compared to the lung epithelial cells and Fgr expression was induced in alveolar macrophages following treatment with silica. These data establish that bone marrow derived as well as native monocyte/ macrophages contribute to the accumulation of inflammatory cells in the lungs of mice that have been injected with crystalline silica. 


\section{A Relative percentage of red senescent cells}
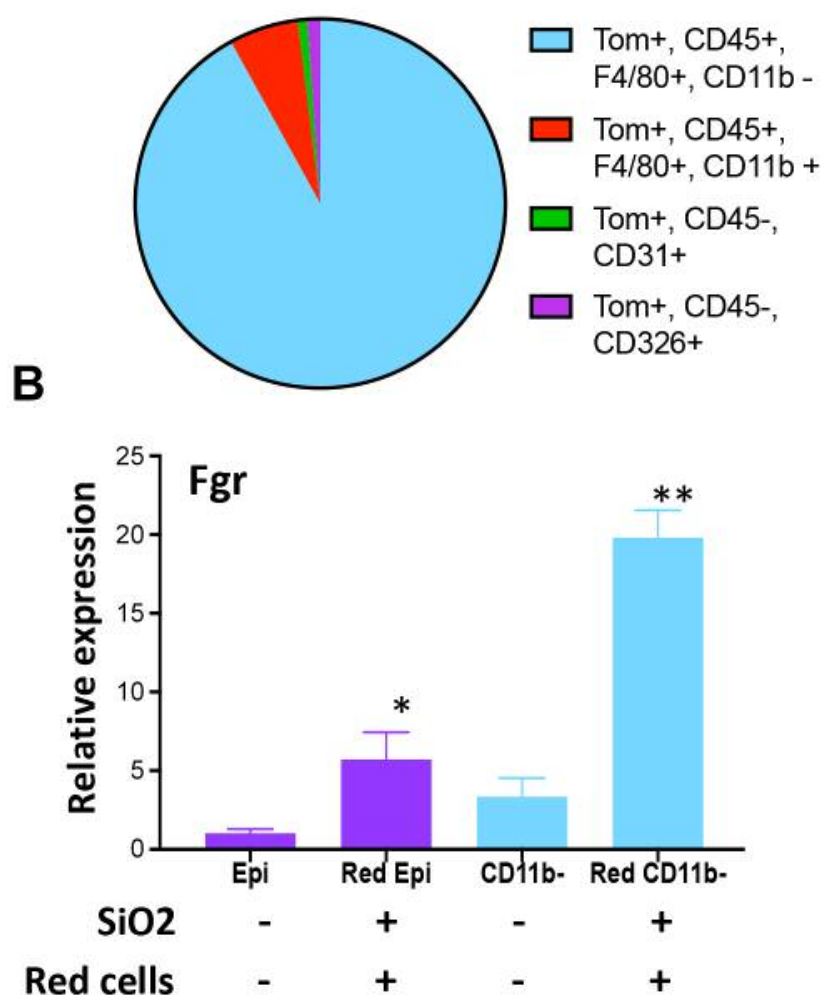

\section{Relative percentage of GFP+ macrophage/monocyte cells}
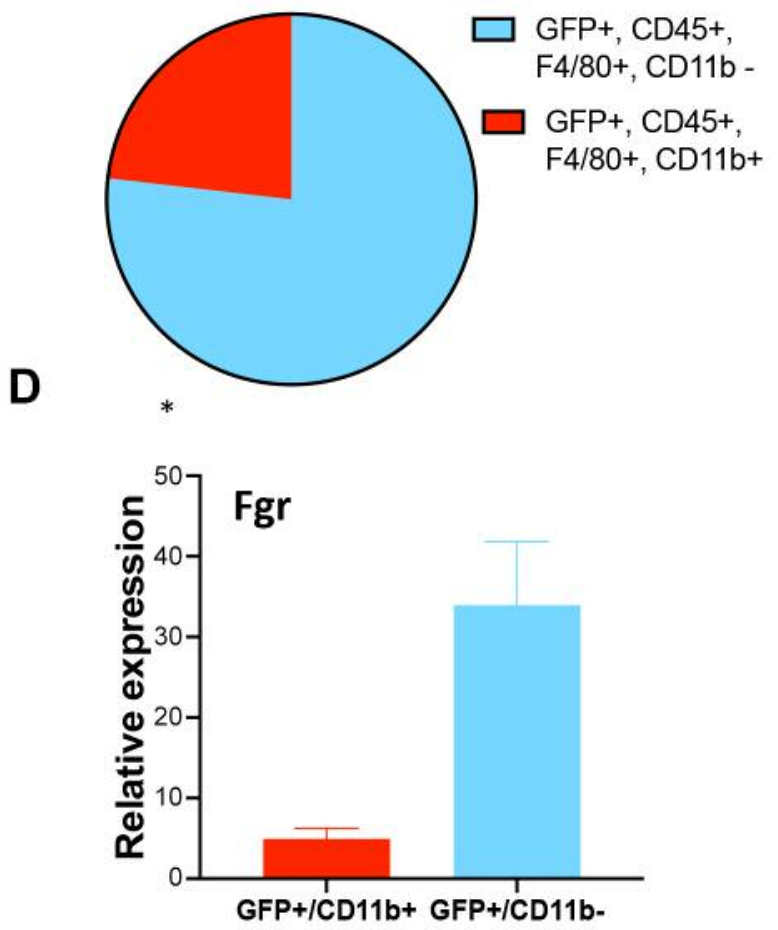

Figure 7. Tyrosine kinase Fgr expression is induced in silica-induced senescent lung cells and in recruited bone marrow monocytes/macrophages. A) Relative percentage of red senescent cells sorted from silica-treated mouse lungs. B) Upregulation of Fgr was observed in senescent epithelial (Tom+, CD45-, CD326+) cells and senescent alveolar (Tom+, CD45+, F4/80+, CD11b-) macrophages. C) Relative percentage of bone marrow origin gfp + macrophage/monocyte cells sorted from gfp chimeric bone marrow, and silica-treated tdTOMp16+ mouse lungs. D) Fgr expression was higher in $\mathrm{gfp}+, \mathrm{CD} 45+, \mathrm{F} 4 / 80+, \mathrm{CD} 11$ - macrophages.

Fgr inhibitor TL02-59 inhibits the senescence cell mediated induction of fibrosis biomarkers in target cells in transwell cultures. To determine the correlation of senescent cells in the lungs with fibrosis to the lungs, we used an in vitro transwell culture system. As shown in Figure 8, radiationinduced (5 Gy, 10 days) tdTOMp16+ bone marrow senescent cells were purified by FACS and were plated at the top well of transwell cultures. The senescent cells in the top chamber of transwell cultures that were separated by a 0.3-micron filter (Figure 8A), induced profibrotic genes in target (mesenchymal stem cells) cells in the bottom chamber of transwell cultures after 10 days including: TFG- $\beta$ and Collagen 3 (Figure 8B). The induction of these biomarkers of fibrosis was blocked by adding to the transwell cultures the small molecule inhibitor of $\mathrm{Fgr}$ kinase TL02-59 (Figure 8B).
Inhibition of tyrosine kinase Fgr by TL02-59 inhibits migration of bone marrow cells towards senescent cells. In a transwell coculture system, we next evaluated the role of Fgr in the migration of GFP bone marrow cells across the 3-micron filter towards the senescent cells (Figure 9B). To determine whether inhibition of tyrosine kinase Fgr in senescent cells blocks the bone marrow migration of gfp + monocyte/macrophages towards the senescent cells at the bottom wells, we added the Fgr tyrosine kinase inhibitor TL02-59 (10nM) in the media and the migrated cells were evaluated after $48 \mathrm{~h}$ of TL02-59 treatment. TL02-59 significantly reduced the migration of gfp+ monocyte/ macrophages towards the senescent cells isolated from irradiated tdTOMp16+ stromal cell line (Figure 9A, C, and D). We observed similar results when we used senescent cells isolated from the tdTOMp16+ lungs 150-days post radiation (Figure 9E and F). We confirmed that the migrating cells were 
A

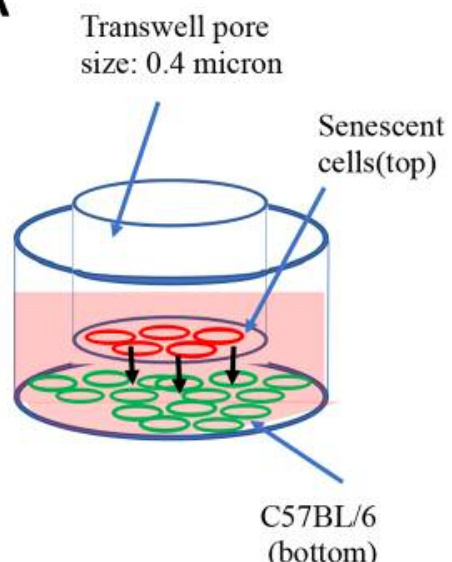

B

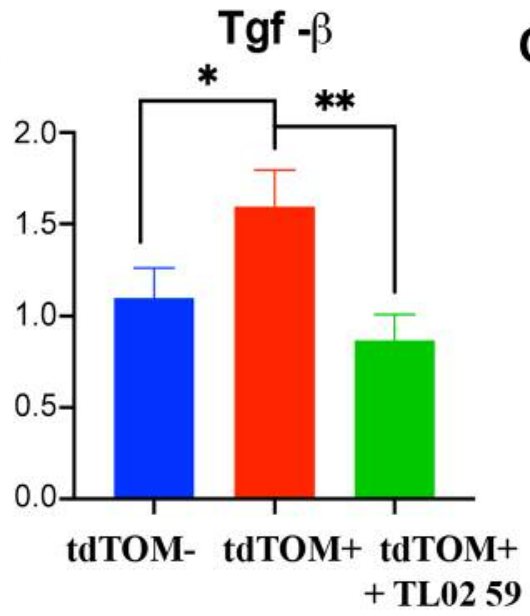

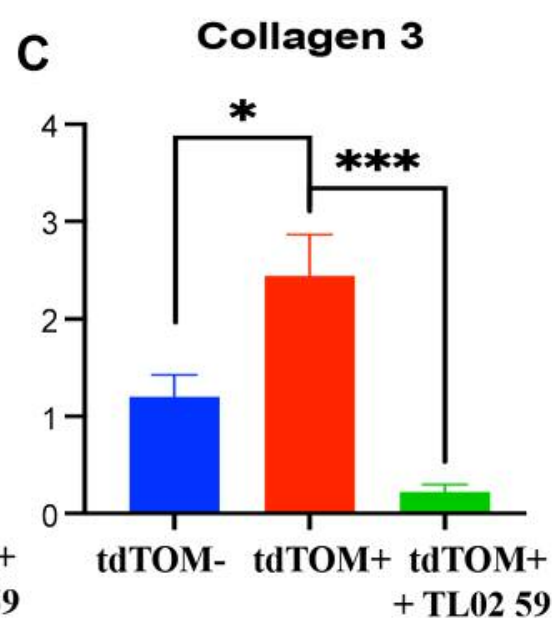

Figure 8. TL02-59 inhibits the induction by senescent cells of fibrosis biomarkers in target cells in transwell cultures. A) tdTOMp16+ cells were either irradiated ( $5 \mathrm{~Gy}$, then sorted 10 days later) or non-sorted. The tdTOMp16+cells were sorted for either tdTOM+ or tdTOM- cells and cultured at the top chamber of each transwell culture well. Target cells were C57BL/6 mouse marrow derived mesenchymal stem cells (MSC) that were cultured in the bottom chamber of each transwell culture separated by a 0.4-micron membrane. Bars show the non-sorted cells (blue bars), sorted TOM+ cells (red bars), or Fgr inhibitor, TL02-59, (10 nM) treated cells (green bars). Ten days later, the target bone marrow cells were harvested and assayed for biomarkers of fibrosis including: $B)$ TGF- $\beta ; C)$ collagen III. $\left(n=2-6,{ }^{*} p \leq 0.05 ; * * p=0.01\right)$. $p$-Values were calculated by the $t$-test.

monocyte/macrophages by adding a monocyte chemotaxis inhibitor, which is a $\mathrm{Ccl} 2$ receptor antagonist (Figure 9A and E). The present results establish that Fgr positive senescent cells recruit the gfp+ bone marrow derived monocyte/macrophage precursors that are separated by a 3-micron filter in a transwell culture system, and that the migration is blocked by a small molecule, which inhibits Fgr, TL02-59.

\section{Discussion}

The sequence of cellular events occurring in the lung during evolution of silicosis and the phenotype(s) of cells that are induced at each stage are not known. In the present study, we focused on the appearance of senescent cells, and, specifically, monocyte/macrophages and neutrophils in the lungs of mice injected with crystalline silica. We corroborated our findings in the radiation-induced pulmonary fibrosis model. We took advantage of the availability of mouse strains, which can be used to demonstrate the link between the occurrence of senescence and upregulation of p16+, a specific biological marker for senescence. The $\mathrm{p} 16^{+/ \mathrm{LUC}}$ mice (37), which can be imaged serially by the IMUS Imaging System, demonstrated senescence-associated p16-linked luciferase activity in the presence of luciferin as early as day 7 after crystalline silica injection. These areas of senescence increased in magnitude through day 28 , when florid fibrosis is detected. Explants of the lungs from these mice as well as control C57BL/6J and tdTOMp16+ (38) mice confirmed the presence of senescent cells in the lungs at the same time points, as the $\mathrm{p} 16^{+/ \mathrm{LUC}}$ imaging results.
The appearance of specific phenotypes of senescent cells in the irradiated lungs of mice has been reported previously (40). The present study extends these findings regarding the kinetics of appearance of senescent cells in the lungs after intratracheal injection of crystalline silica in mice. Senescent cells in the lungs were demonstrated to be primarily monocytes/macrophages. Furthermore, bone marrow derived monocytes/macrophages were demonstrated in the lungs of gfp + marrow chimeric mice that had developing silicosis. Increasing numbers of resident (recipient origin) pulmonary epithelial cells and monocytes/macrophages were observed to be senescent. After crystalline silica intratracheal injection, gfp+ bone marrow chimeric tdTOMp16+ mice demonstrated significant bone marrow derived monocytes/macrophages in the lungs, and these cells were positive for the senescenceassociated Fgr tyrosine kinase as well as other biomarkers of senescence including p16.

To confirm that crystalline silica-injected senescent mouse lung cells were recruiting bone marrow derived monocytes/ macrophages, we established a transwell culture system in which senescent cells on the bottom were separated from gfp+ bone marrow cells in the top of the transwell separated by 3 -micron filter. In these experiments, we used radiation-induced senescent cells, which recruited gfp+ monocytes/macrophages through the filter, and these bone marrow derived cells accumulated on the bottom surface of the filter. Migration of gfp+ bone marrow cells in response to senescent cells was inhibited by the small molecule Fgr inhibitor TL02-59. The role of Fgr in senescent cells and in pulmonary fibrosis has been a subject of recent interest. Tyrosine kinases are involved in many inflammatory and fibrotic processes 


\section{A}
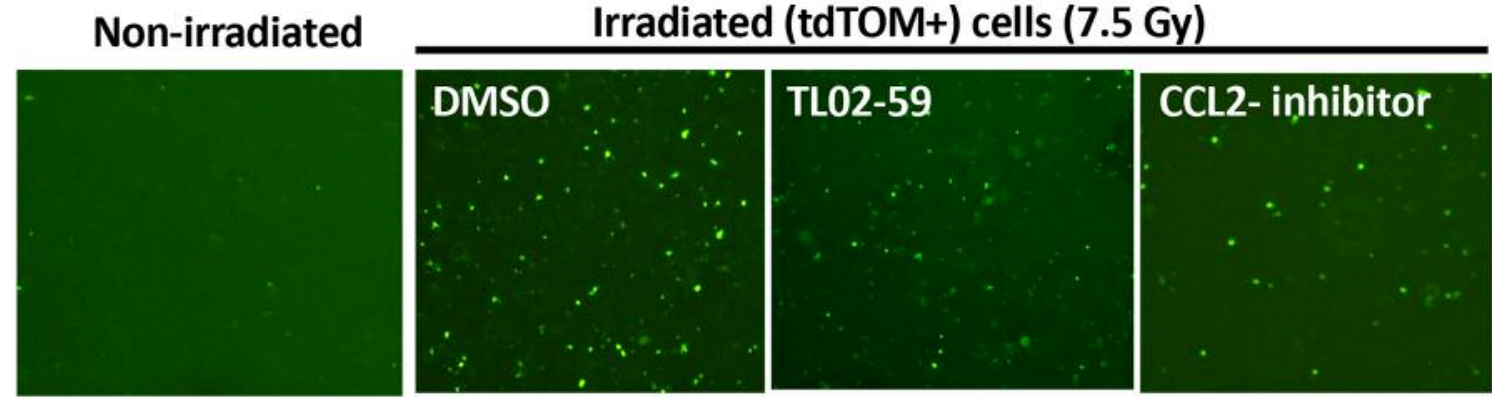

B

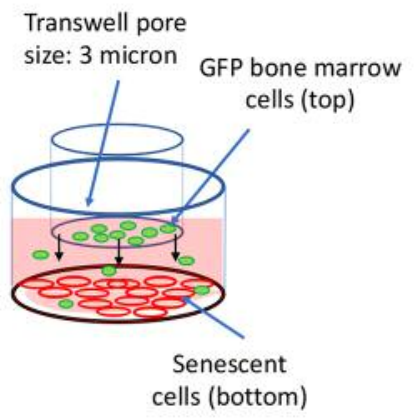

C

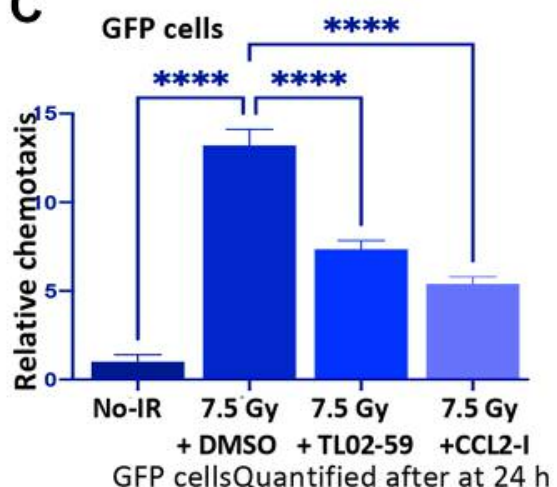

D

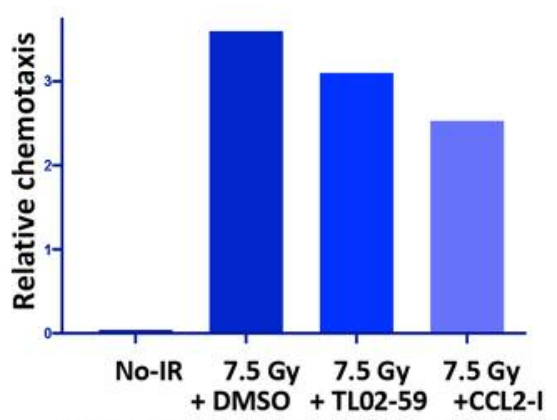

By FACS sorting for immune cells at $48 \mathrm{~h}$
E
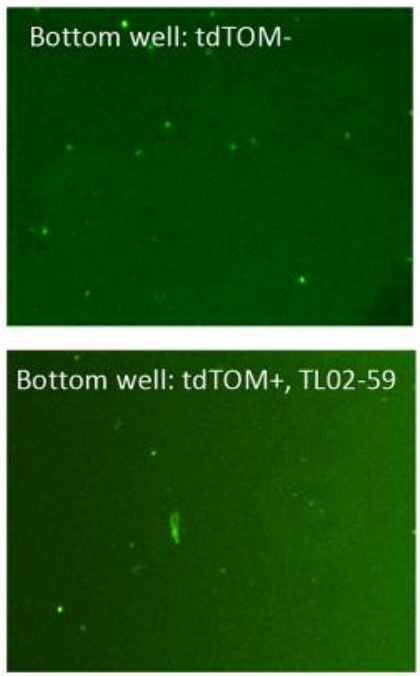

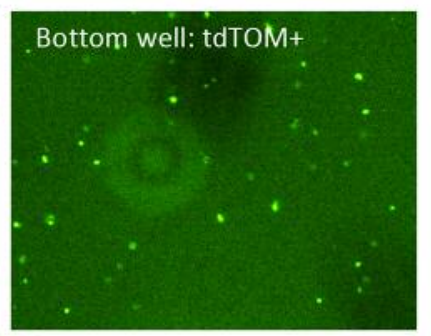

Bottom well: tdTOM+, $\mathrm{Ccl} 2 \mathrm{i}$

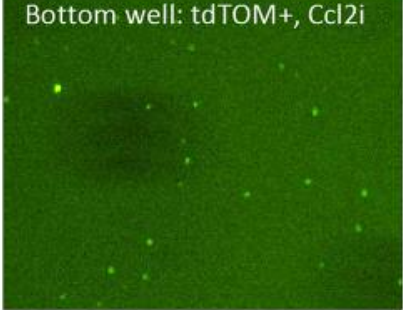

$\mathbf{F}$

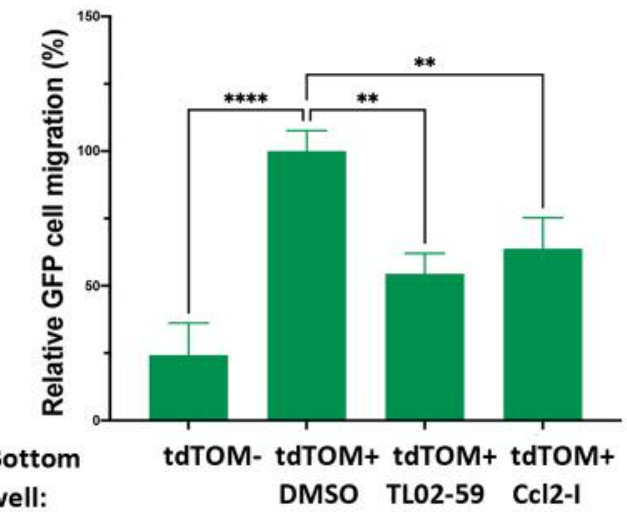

Figure 9. Inhibition of tyrosine kinase Fgr by TL02-59 prevents migration of bone marrow cells towards senescent cells. The tdTOMp16+ cells either irradiated or non-irradiated were sorted by FACS for either tdTOM+ or tdTOM-cells, and each population was placed in the bottom chamber of each culture, well separated by a 3-micron filter. Gfp+ bone marrow cells were placed on the top chamber of each well and migration assay was carried out (3-micron membrane). The Fgr inhibitor TL02-59(10 nM) (41) or RS $504393(10 \mu M)$, a Ccl2 inhibitor, which is a CCR2 chemokine receptor antagonist, was added to cultures 24 h later. The migration of gfp + bone marrow cells from the top chamber through the 3-micron filter to the bottom chamber was imaged and total gfp + cells were counted. B) Image of gfp + migrating cells through the filter at $24 \mathrm{~h}$ for each condition ( $\times 100)$. At $48 \mathrm{~h}$, emigrated gfp + cells in the bottom well were counted by FACS. After 48 h, migrating total, C) gfp + cells, and D) gfp $+C D 45+$ cells were counted by FACS. E) Senescent tdTOM+ lung cells sorted from irradiated mouse lungs were plated at the bottom wells and Fgr kinase inhibitor (TL02-59, $10 \mathrm{nM}$ ) or Ccl2-inhibitor RS 504393 (Ccl2i, $10 \mu \mathrm{M})$ was added for $12 \mathrm{~h}$ before adding GFP positive mouse bone marrow cells on the top wells. Cell migration from the top wells to the bottom wells was evaluated by imaging and by F) FACS analysis. $(n=3$; **** $p=0.0001)$. $p$-Values were calculated by the t-test. 
(45-52). Using transwell cultures, we showed that inhibition of Fgr reduced their capacity to induce biomarkers of fibrosis in target cells and to induce chemotaxis of gfp+ marrow origin cells. We also demonstrated that areas of fibrosis were present in the lungs of crystalline silica-injected mice juxtaposed to the areas that showed p16 positive senescent epithelial cells. Interestingly single cell suspensions from whole lungs revealed that senescent cells were predominantly of the monocyte/macrophage phenotype and a significant percentage were of bone marrow origin. The sequence and time course of these cellular events is currently being studied.

The present data establish that cells of bone marrow origin are a component of the monocyte/macrophage and neutrophil response in the lungs during the development of silicosis. They also document the appearance of senescent cells in the lungs in areas of fibrosis. Further studies will be required to elucidate clearly and specifically the interaction between pulmonary epithelial cells, resident alveolar and interstitial macrophages with bone marrow derived migrating monocyte/macrophages, and the cell phenotype of those cells accumulating alpha-smooth muscle actin and proliferating fibroblasts to form fibrosis.

\section{Conflicts of Interest}

The Authors declare that they have no conflicts of interest in relation to this study.

\section{Authors' Contributions}

Michael W. Epperly, Joel S. Greenberger and Luis A. Ortiz conceptualized the study; Amitava Mukherjee, Michael W. Epperly, Renee Fisher contributed in methodology; Amitava Mukherjee, Michael W. Epperly, Renee Fisher, Wen Hou, Donna Shields performed the investigation; Joel S. Greenberger and Amitava Mukherjee wrote the original draft of the manuscript and Michael W. Epperly, Joel S. Greenberger, Luis A. Ortiz and Amitava Mukherjee reviewed and edited the manuscript; Hong Wang and Amitava Mukherjee performed statistical analyses; Joel S. Greenberger acquired funding and provided resources; Michael W. Epperly and Joel S. Greenberger were responsible for study supervision.

\section{Acknowledgements}

Supported by Grant U19AI1068021 of National Institute of Allergy and Infectious Diseases/National Institutes of Health (NIAID/NIH), MA, U.S.A.

\section{References}

1 Mossman BT and Churg A: Mechanisms in the pathogenesis of asbestosis and silicosis. Am J Respir Crit Care Med 157(5 Pt 1): 1666-1680, 1998. PMID: 9603153. DOI: 10.1164/ajrccm. 157.5.9707141

2 Adverse effects of crystalline silica exposure. American Thoracic Society Committee of the Scientific Assembly on Environmental and Occupational Health. Am J Respir Crit Care Med 155(2): 761768, 1997. PMID: 9032226. DOI: 10.1164/ajrccm.155.2.9032226

3 Lemaire I: Silica- and asbestos-induced pulmonary fibrosis. In: Pulmonary fibrosis. Phan SH, Thrall RS (eds.). Marcel Dekker, New York. pp. 319-362, 1995.

4 OSHA. Occupational exposure to crystalline silica. Semiannual regulatory agenda. Fed Reg 68:30583-30594, 2003. Available at: http://www.osha.gov/SLT/silicacrystalline/standards.html [Last accessed on September 27, 2004]

5 Yassin A, Yebesi $F$ and Tingle R: Occupational exposure to crystalline silica dust in the United States, 1988-2003. Environ Health Perspect 113(3): 255-260, 2005. PMID: 15743711. DOI: 10.1289/ehp.7384

6 Rosenman KD, Reilly MJ and Henneberger PK: Estimating the total number of newly-recognized silicosis cases in the United States. Am J Ind Med 44(2): 141-147, 2003. PMID: 12874846. DOI: $10.1002 /$ ajim.10243

7 Morbidity and Mortality weekly Report (MMWR). Silicosis Mortality, Prevention, and Control-United States 1968-2002. April 29, 2005. Available at: http://www2a.cdc.gov/drds/ WorldReportData/ [Last accessed on September 15, 2021]

8 Petsonk EL, Rose C and Cohen R: Coal mine dust lung disease. New lessons from old exposure. Am J Respir Crit Care Med 187(11): 1178-1185, 2013. PMID: 23590267. DOI: 10.1164/ rccm.201301-0042CI

9 Cohen RA, Petsonk EL, Rose C, Young B, Regier M, Najmuddin A, Abraham JL, Churg A and Green FH: Lung pathology in U.S. coal workers with rapidly progressive pneumoconiosis implicates silica and silicates. Am J Respir Crit Care Med 193(6): 673-680, 2016. PMID: 26513613. DOI: 10.1164/rccm.201505-1014OC

10 OSHA's Final Rule to Protect Workers from Exposure to Respirable Crystalline Silica. Available at: https://ehssafetynewsamerica.com/2016/03/29/oshas-final-ruleto-protect-workers-from-exposure-to-respirable-crystallinesilica/ [Last accessed on September 15, 2021]

11 Almberg KS, Friedman LS, Swedler D and Cohen RA: Mine Safety and Health Administration's Part 50 program does not fully capture chronic disease and injury in the Illinois mining industry. Am J Ind Med 61(5): 436-443, 2018. PMID: 29521422. DOI: $10.1002 /$ ajim. 22826

12 Coal deadly dust (PBS investigative series Frontline, NPR (1/22/2019, Berkes). Available at: https://www.pbs.org/wgbh/ frontline/film/coals-deadly-dust/ [Last accessed on September $15,2021]$

13 Almberg KS, Halldin CN, Blackley DJ, Laney AS, Storey E, Rose CS, Go LHT and Cohen RA: Progressive massive fibrosis resurgence identified in U.S. coal miners filing for black lung benefits, 1970-2016. Ann Am Thorac Soc 15(12): 1420-1426, 2018. PMID: 30114941. DOI: 10.1513/AnnalsATS.2018042610C

14 Di Giuseppe M, Gambelli F, Hoyle GW, Lungarella G, Studer SM, Richards T, Yousem S, McCurry K, Dauber J, Kaminski N, Leikauf $G$ and Ortiz LA: Systemic inhibition of NF-kappaB activation protects from silicosis. PLoS One 4(5): e5689, 2009. PMID: 19479048. DOI: 10.1371/journal.pone.0005689

15 He Y, Thummuri D, Zheng G, Okunieff P, Citrin DE, Vujaskovic $\mathrm{Z}$ and Zhou D: Cellular senescence and radiation-induced pulmonary fibrosis. Transl Res 209: 14-21, 2019. PMID: 30981698. DOI: $10.1016 /$ j.trs1.2019.03.006 
16 Morimoto Y, Nagatomo H, Hirohashi M, Oyabu T, Ogami A, Yamato $\mathrm{H}$, Kuroda $\mathrm{K}$, Obata $\mathrm{Y}$, Higashi $\mathrm{T}$ and Tanaka I: Expression of clara cell secretory protein in the lungs of rats exposed to crystalline silica in vivo. J Occup Health 47(6): 504509, 2005. PMID: 16369113. DOI: 10.1539/joh.47.504

17 Wynn TA and Ramalingam TR: Mechanisms of fibrosis: therapeutic translation for fibrotic disease. Nat Med 18(7): 10281040, 2012. PMID: 22772564. DOI: 10.1038/nm.2807

18 Koch CM, Chiu SF, Misharin AV and Ridge KM: Lung interstitial macrophages: Establishing identity and uncovering heterogeneity. Am J Respir Cell Mol Biol 57(1): 7-9, 2017 PMID: 28665216. DOI: 10.1165/rcmb.2017-0150ED

19 Bharat A, Bhorade SM, Morales-Nebreda L, McQuattiePimentel AC, Soberanes S, Ridge K, DeCamp MM, Mestan KK, Perlman H, Budinger GR and Misharin AV: Flow cytometry reveals similarities between lung macrophages in humans and mice. Am J Respir Cell Mol Biol 54(1): 147-149, 2016. PMID: 26274047. DOI: $10.1165 / \mathrm{rcmb} .2015-0147 \mathrm{LE}$

20 Misharin AV, Morales-Nebreda L, Reyfman PA, Cuda CM, Walter JM, McQuattie-Pimentel AC, Chen CI, Anekalla KR, Joshi N, Williams KJN, Abdala-Valencia H, Yacoub TJ, Chi M, Chiu S, Gonzalez-Gonzalez FJ, Gates K, Lam AP, Nicholson TT, Homan PJ, Soberanes S, Dominguez S, Morgan VK, Saber R, Shaffer A, Hinchcliff M, Marshall SA, Bharat A, Berdnikovs S, Bhorade SM, Bartom ET, Morimoto RI, Balch WE, Sznajder JI, Chandel NS, Mutlu GM, Jain M, Gottardi CJ, Singer BD, Ridge KM, Bagheri N, Shilatifard A, Budinger GRS and Perlman H: Monocyte-derived alveolar macrophages drive lung fibrosis and persist in the lung over the life span. J Exp Med 214(8): 2387-2404, 2017. PMID: 28694385. DOI: 10.1084/jem. 20162152

21 Byrne AJ, Maher TM and Lloyd CM: Pulmonary macrophages: A new therapeutic pathway in fibrosing lung disease? Trends Mol Med 22(4): 303-316, 2016. PMID: 26979628. DOI: 10.1016/j.molmed.2016.02.004

22 Dal-Secco D, Wang J, Zeng Z, Kolaczkowska E, Wong CH, Petri B, Ransohoff RM, Charo IF, Jenne CN and Kubes P: A dynamic spectrum of monocytes arising from the in situ reprogramming of CCR2+ monocytes at a site of sterile injury. J Exp Med 212(4): 447-456, 2015. PMID: 25800956. DOI: 10.1084/jem.20141539

23 Bhattacharya $\mathrm{J}$ and Westphalen K: Macrophage-epithelial interactions in pulmonary alveoli. Semin Immunopathol 38(4): 461-469, 2016. PMID: 27170185. DOI: 10.1007/s00281-016$0569-\mathrm{x}$

24 Garantziotis S: Myofibroblast-macrophage interactions turn sour in fibrotic lungs. Am J Respir Cell Mol Biol 64(1): 14-15, 2021 PMID: 33166479. DOI: $10.1165 / \mathrm{rcmb} .2020-0473 \mathrm{ED}$

25 Ortiz LA, Dutreil M, Fattman C, Pandey AC, Torres G, Go K and Phinney DG: Interleukin 1 receptor antagonist mediates the antiinflammatory and antifibrotic effect of mesenchymal stem cells during lung injury. Proc Natl Acad Sci U.S.A. 104(26): 11002-11007, 2007. PMID: 17569781. DOI: 10.1073/pnas. 0704421104

26 Galván-Peña S, Carroll RG, Newman C, Hinchy EC, PalssonMcDermott E, Robinson EK, Covarrubias S, Nadin A, James AM, Haneklaus M, Carpenter S, Kelly VP, Murphy MP, Modis LK and O'Neill LA: Malonylation of GAPDH is an inflammatory signal in macrophages. Nat Commun 10(1): 338, 2019. PMID: 30659183. DOI: 10.1038/s41467-018-08187-6
27 Redente EF, Keith RC, Janssen W, Henson PM, Ortiz LA, Downey GP, Bratton DL and Riches DW: Tumor necrosis factor$\alpha$ accelerates the resolution of established pulmonary fibrosis in mice by targeting profibrotic lung macrophages. Am J Respir Cell Mol Biol 50(4): 825-837, 2014. PMID: 24325577. DOI: 10.1165/rcmb.2013-0386OC

28 Muñoz-Espın D and Serrano M: Cellular senescence: from physiology to pathology. Nat Rev Mol Cell Biol 15: 482-496, 2014. PMID: 24954210. DOI: $10.1038 / \mathrm{nrm} 3823$

29 Coppé JP, Desprez PY, Krtolica A and Campisi J: The senescence-associated secretory phenotype: the dark side of tumor suppression. Annu Rev Pathol 5: 99-118, 2010. PMID: 20078217. DOI: 10.1146/annurev-pathol-121808-102144

30 Yao C, Guan X, Carraro G, Parimon T, Liu X, Huang G, Mulay A, Soukiasian HJ, David G, Weigt SS, Belperio JA, Chen P, Jiang D, Noble PW and Stripp BR: Senescence of alveolar type 2 cells drives progressive pulmonary fibrosis. Am J Respir Crit Care Med 203(6): 707-717, 2021. PMID: 32991815. DOI: 10.1164/rccm.202004-1274OC

31 Schafer MJ, White TA, Iijima K, Haak AJ, Ligresti G, Atkinson EJ, Oberg AL, Birch J, Salmonowicz H, Zhu Y, Mazula DL, Brooks RW, Fuhrmann-Stroissnigg H, Pirtskhalava T, Prakash YS, Tchkonia T, Robbins PD, Aubry MC, Passos JF, Kirkland JL, Tschumperlin DJ, Kita $\mathrm{H}$ and LeBrasseur NK: Cellular senescence mediates fibrotic pulmonary disease. Nat Commun 8: 14532, 2017. PMID: 28230051. DOI: $10.1038 /$ ncomms 14532

32 Childs BG, Gluscevic M, Baker DJ, Laberge RM, Marquess D, Dananberg J and van Deursen JM: Senescent cells: an emerging target for diseases of ageing. Nat Rev Drug Discov 16(10): 718735, 2017. PMID: 28729727. DOI: 10.1038/nrd.2017.116

33 Yun MH: Cellular senescence in tissue repair: every cloud has a silver lining. Int J Dev Biol 62(6-7-8): 591-604, 2018. PMID: 29938770. DOI: $10.1387 /$ ijdb.180081my

34 Campisi J and d'Adda di Fagagna F: Cellular senescence: when bad things happen to good cells. Nat Rev Mol Cell Biol 8(9): 729-740, 2007. PMID: 17667954. DOI: $10.1038 / \mathrm{nrm} 2233$

35 Sharpless NE and Sherr CJ: Forging a signature of in vivo senescence. Nat Rev Cancer 15(7): 397-408, 2015. PMID: 26105537. DOI: $10.1038 / \mathrm{nrc} 3960$

36 Epperly MW, Guo H, Gretton JE and Greenberger JS: Bone marrow origin of myofibroblasts in irradiation pulmonary fibrosis. Am J Respir Cell Mol Biol 29(2): 213-224, 2003. PMID: 12649121. DOI: $10.1165 / \mathrm{rcmb} .2002-00690 \mathrm{C}$

37 Liu JY, Souroullas GP, Diekman BO, Krishnamurthy J, Hall BM, Sorrentino JA, Parker JS, Sessions GA, Gudkov AV and Sharpless NE: Cells exhibiting strong p16 INK4a promoter activation in vivo display features of senescence. Proc Natl Acad Sci U.S.A. 116(7): 2603-2611, 2019. PMID: 30683717. DOI: 10.1073/pnas.1818313116

38 Sessions GA, Copp ME, Liu JY, Sinkler MA, D'Costa S and Diekman BO: Controlled induction and targeted elimination of p16 ${ }^{\text {INK4a }}$-expressing chondrocytes in cartilage explant culture. FASEB J 33(11): 12364-12373, 2019. PMID: 31408372. DOI: 10.1096/fj.201900815RR

39 Kalash R, Epperly MW, Goff J, Dixon T, Sprachman MM, Zhang X, Shields D, Cao S, Franicola D, Wipf P, Berhane H, Wang $\mathrm{H}, \mathrm{Au} \mathrm{J}$ and Greenberger JS: Amelioration of radiationinduced pulmonary fibrosis by a water-soluble bifunctional sulfoxide radiation mitigator (MMS350). Radiat Res 180(5): 474-490, 2013. PMID: 24125487. DOI: 10.1667/RR3233.1 
40 Epperly MW, Shields D, Fisher R, Hou W, Wang H, Hamade DF, Mukherjee A and Greenberger JS: Radiation-induced senescence in p16+/LUC mouse lung compared to bone marrow multilineage hematopoietic progenitor cells. Radiat Res 196(3): 235-249, 2021. PMID: 34087939. DOI: 10.1667/RADE-20-00286.1

41 Shen K, Moroco JA, Patel RK, Shi H, Engen JR, Dorman HR and Smithgall TE: The Src family kinase Fgr is a transforming oncoprotein that functions independently of SH3-SH2 domain regulation. Sci Signal 11(553): eaat5916, 2018. PMID: 30352950. DOI: $10.1126 /$ scisignal.aat5916

42 Ejaz A, Epperly MW, Hou W, Greenberger JS and Rubin JP: Adipose-derived stem cell therapy ameliorates ionizing irradiation fibrosis via hepatocyte growth factor-mediated transforming growth factor- $\beta$ downregulation and recruitment of bone marrow cells. Stem Cells 37(6): 791-802, 2019. PMID: 30861238. DOI: $10.1002 /$ stem.3000

43 Li H, Zhao C, Tian Y, Lu J, Zhang G, Liang S, Chen D, Liu X, Kuang $\mathrm{W}$ and Zhu M: Src family kinases and pulmonary fibrosis: A review. Biomed Pharmacother 127: 110183, 2020. PMID: 32388241. DOI: 10.1016/j.biopha.2020.110183

44 Misharin AV, Morales-Nebreda L, Mutlu GM, Budinger GR and Perlman H: Flow cytometric analysis of macrophages and dendritic cell subsets in the mouse lung. Am J Respir Cell Mol Biol 49(4): 503-510, 2013. PMID: 23672262. DOI: 10.1165/ rcmb.2013-0086MA

45 Lowell CA: Src-family kinases: rheostats of immune cell signaling. Mol Immunol 41(6-7): 631-643, 2004. PMID: 15220000. DOI: 10.1016/j.molimm.2004.04.010

46 Okutani D, Lodyga M, Han B and Liu M: Src protein tyrosine kinase family and acute inflammatory responses. Am J Physiol Lung Cell Mol Physiol 291(2): L129-L141, 2006. PMID: 16581827. DOI: 10.1152/ajplung.00261.2005

47 Meng F and Lowell CA: Lipopolysaccharide (LPS)-induced macrophage activation and signal transduction in the absence of Src-family kinases Hck, Fgr, and Lyn. J Exp Med 185(9): 16611670, 1997. PMID: 9151903. DOI: 10.1084/jem.185.9.1661
48 Acín-Pérez R, Iborra S, Martí-Mateos Y, Cook ECL, CondeGarrosa R, Petcherski A, Muñoz MDM, Martínez de Mena R, Krishnan KC, Jiménez C, Bolaños JP, Laakso M, Lusis AJ, Shirihai OS, Sancho D and Enríquez JA: Fgr kinase is required for proinflammatory macrophage activation during diet-induced obesity. Nat Metab 2(9): 974-988, 2020. PMID: 32943786. DOI: 10.1038/s42255-020-00273-8

49 Jing X, Ren D, Gao F, Chen Y, Wu X, Han Y, Han Q, Li L, Wang $\mathrm{X}$, Tang $\mathrm{W}$ and Zhang Y: Gene deficiency or pharmacological inhibition of PDCD4-mediated FGR signaling protects against acute kidney injury. Acta Pharm Sin B 11(2): 394-405, 2021. PMID: 33643819. DOI: 10.1016/j.apsb.2020.10.024

50 Lowell CA, Fumagalli L and Berton G: Deficiency of Src family kinases p59/61hck and p58c-fgr results in defective adhesiondependent neutrophil functions. J Cell Biol 133(4): 895-910, 1996. PMID: 8666673. DOI: 10.1083/jcb.133.4.895

51 Kovács M, Németh T, Jakus Z, Sitaru C, Simon E, Futosi K, Botz B, Helyes Z, Lowell CA and Mócsai A: The Src family kinases Hck, Fgr, and Lyn are critical for the generation of the in vivo inflammatory environment without a direct role in leukocyte recruitment. J Exp Med 211(10): 1993-2011, 2014. PMID: 25225462. DOI: 10.1084/jem.20132496

52 Ingley E: Src family kinases: regulation of their activities, levels and identification of new pathways. Biochim Biophys Acta 1784(1): 56-65, 2008. PMID: 17905674. DOI: 10.1016/j.bbapap. 2007.08 .012
Received August 20, 2021

Revised September 13, 2021 Accepted September 15, 2021 